\section{EFFECTS OF CARBON DIOXIDE ON THE HEART AND CIRCULATION}

$I^{N}$

his presidential address to the Physiology Section of the thirty-first Indian Science Congress held in January, Dr. S. N. Mathur discussed the physiological importance of carbon dioxide. Carbon dioxide has generally been regarded as a toxic waste product which the body seeks to eliminate as rapidly as possible, but it is now well recognized that it has certain beneficial actions as well. Originally a necessary evil, it has, in the course of evolution, so inextricably worked its way into the body machinery that it has come to be indispensable for certain physiological processes. The necessity of carbon dioxide for maintaining the $p \mathrm{H}$ of the blood and the activity of the respiratory centre is, of course, well known; its importance for the proper working of the cardio-vascular system is less well appreciated, and this field, in which Dr. Mathur has made important observations, may be worth a brief review.

The fundamental experiments have been made on anæsthetized cats and dogs. The carbon dioxide content of the blood was increased by inhalation of carbon dioxide and decreased by forced breathing (hyperventilation). The most striking effect is on the arterial blood pressure, increase of carbon dioxide causing a rise of pressure, decrease a fall. This effect is due. to the direct action of carbon dioxide on the vasomotor centre, the normal 'tone' of which is dependent on the continual stimulus of carbon dioxide. In addition, carbon dioxide has a peripheral action on the capillaries causing dilatation, which tends to cause a fall of blood pressure; normally, however, the central effect predominates and the net result is a rise.

In anæsthetized animals, increase of carbon dioxide causes slowing of the heart (sometimes there is a transitory initial acceleration). The slowing is partly reflex from the rise of blood pressure, but is mainly due to the direct action of carbon dioxide on the cardio-inhibitory centre. Conversely, hyperventilation causes acceleration of the heart.

Increase of carbon dioxide causes a considerable increase in the stroke volume of the heart, so that, despite the reduced heart-rate, the total output per minute is increased. The increase in stroke volume is due to increased diastolic filling, and it was thought that this was simply due to the rise of venous pressure which usually occurs. Dr. Mathur has shown, however, that the increase in cardiac output can occur quite independently of the rise of venous pressure, and he believes that earbon dioxide has a direct action on the heart-muscle, increasing the diastolic relaxation of the ventricle. When the carbon dioxide is reduced by hyperventilation, the cardiac output falls owing to reduced diastolic relaxation of the ventricle. He emphasizes this beneficial action of carbon dioxide on the heart in promoting diastolic relaxation and so allowing greater filling, which, owing to the intrinsic properties of cardiac muscle, automatically gives rise to increased output. He believes, further, that this increased cardiac output is an important contributory factor to the rise of blood pressure.

Previous workers had usually reported a reduction of cardiac output following administration of carbon dioxide. Dr. Mathur found that the increase of output with carbon dioxide was only to be obtained during the first hour or two of the experiment, while the heart was 'fresh'; after several hours of anæsthesia, the heart became 'stale' and then carbon dioxide caused a reduction of output. This seems to explain the discrepancies in the reported results. It seems rather surprising that an increase of carbon dioxide above the normal level should actually improve the efficiency of the heart. The general outcome, however, is quite clear, that a normal level of carbon dioxide in the blood is necessary for the maintenance of normal vasomotor tone, normal heartrate and normal diastolic relaxation of the heart; these must all be reckoned as beneficial effects.

The general interpretation of these cardio-vascular responses to an increase of carbon dioxide is that the circulation-rate is increased in order to hasten removal of carbon dioxide. The slowing of the heart is, therefore, somewhat surprising ; an acceleration would seem more appropriate. Dr. Mathur regards the slowing as a protective device, enabling the heart to conserve its energy so that it can survive longer under asphyxial conditions. It remains to be seen, however, if the slowing is a general phenomenon; perhaps it only occurs under anæsthesia. In man, inhalation of carbon dioxide always causes acceleration. In the whole animal the problem is complicated by the fact that the increased respiratory movements cause changes in the venous return which reflexly affect the heart-rate and the output. It is very difficult to disentangle these effects from the direct effects of carbon dioxide, and the whole problem requires further analysis. $\quad$ O. A. TroweII.

\section{ECONOMIC EXPLOITATION OF EUROPE AND ITS CONSEQUENCES}

$7 \mathrm{HE}$ analysis of German economic policy for Europe which was issued by the Royal Institute of International Affairs in March 1941 under the title "Europe Under Hitler : In Prospect and Practice" has now been followed by a further study, "Occupied Europe: German Exploitation and its Post-war Consequences"*. The measure of the change in the situation during the three years may be seen in the structure of the two booklets. The first emphasized the two parts of German economic policy : a short-term plan for the duration of the War; and a long-term plan for the permanent organization of Europe. The first booklet discussed both, but while the first part of the new study examines Germany's domination over occupied Europe and the mobilization and exploitation of its resources up to the auturnn of 1943 , the implications of a permanent German 'New Order' are no longer considered. Instead, the second part dealing with the post-war period discusses some of the problems to be faced during and after liberation, and in a couple of dozen pages gives a lucid account of the implications of German domination and the conditions which any plans for rehabilitation and reconstruction must seek to meet.

The first part of the booklet points out that, whether by military or political measures, the Germans have bereft all the occupied countries of their freedom. All resources, both material and human, have been mobilized for the benefit of Germany and often transferred to Germany, while under the

* "Occupied Europe: German Exploitation and its Post-War Consequences. Pp. 75. (London: Royal Institute of International Consequences. Pp. 